\title{
A study of South Asian Refugee's Settlement Experiences in Estonia
}

\author{
Aminul Islam \\ Tallinn University, Estonia
}

\section{Introduction}

In a constant changing world, societies that remained homogenous are quickly turning a remnant of the past. Continuous migration, intercultural communication, agreements, cooperation, war, societal, financial and political conflicts all testify to the fact that we are going through on an age of diversity. In a multiethnic society, people having multiple identities are trying to use different strategies to achieve their goals; and to achieve them, they face different experiences (Sharmin 2008). Therefore, new argument emerged regarding the extent it is possible to ensure immigrants own identity at the same time to cope new culture of a host society. It is also a matter of fact whether it affects the same way in different heterogeneous migrant people. Sociological theories and research have generally focused on specific aspects on forced migrants such as, demographic characteristic of refugees, decision making, economic and psychological adaptation of refugees in the receiving countries are the most focused aspects on forced migration issues. (Richmond 1988). Issues surrounding integration and settlement of refugees remain largely on mental health of refugees into new societies and most literatures don't provide a detailed argument about how "culture shock" resulting from resettlement into a new society(Nourpannah 2014). "There is an extensive scholarly literature criticizing politically silenced and deliberately muted construct of refugees"(58). Popular images of refugees in the society are as victim and perhaps they suffer agency ( Nyers 2006). Is this the case for all refugees or it is a metaphor? By studying the specific setting of refugees in Estonia, this study will enhance our understanding of the experiences of refugees and their subsequent settlement.

It is quite often perceived that humanitarianism is the ideology of hegemonic states in the era of globalization. Chimni (2000) in her study of relationship of globalization and humanitarianism stated that "while humanitarianism has always had a presence in the international politics, it has never had the salience it 
possesses in the recent days"(244). This has not been changed even in the recent time. Dandy(2009) in her research shown refugees and their resettlement issues and how could itaffect even a local level with the power of hegemony which exists in the globalized world. While the discussion on refugees and their resettlement goes on along with hegemonic discourse, the numbers of refugees have been increasing all over the world. EU countries for instance have received more than six hundred thousand asylum seekers in 2014 compared to 2013, when the number was around four hundred thousand (Eurostat, 2015), which makes the evaluation percentage from 2013 to 2014 as fourteen percent. Estonia joined the European Union in 2004 and Schengen area in 2007. In 1997 Estonia ratified the 1951 convention relating to the status of refugees and the corresponding 1967 protocol (UNHCR). Estonia has traditionally viewed as least attractive country for asylum seekers. According to an Estonian newspaper, it might be the case that Estonian living standard is lower than those of its neighboring countries (Marian 2015). Estonian Human rights center in their report on refugees addressed that the number of asylum seekers has been quite low and it might be the case that general public is not aware of this issue and unfortunately this topic has not been a priority on the governmental level either (EHRC 2015). In this report, Estonian Human rights center actually used their data up to the year 2011. In 2009 the number of asylum seekers in Estonia was 40 and in 2011 it was 67. Most recent data from Eurostat though represents a very significant story, as of 2013 the number of asylum seekers in Estonia was 95 and in 2014 it went high up to 155 and the evaluation rate is 63 percent which is even higher than overall EU rate. It's a significant number for a country which has only 1.3 million populations. Therefore, Estonia as a global society and a part of European Union and its organizations that deal with asylum seekers and refugees might face new challenges.

The research question and fieldwork for this study came out of a curiosity to study the resettlement experiences of South Asian refugees living in Estonia, which doesn't have sizeable multiethnicrefugee population that are found in other European Union countries, despite the fact of very fast growing number of refugees that paced up in the recent years. From a socio-cultural point of view, South Asian refugees in this study comprised of Afghan, Pakistani and Bangladeshi, who share same religion and in most cases language wise they understand each other as languages are somewhat similar and most of them know Hindi, which is widely spoken and understood in that region. This study was carried out to construct an understanding of the integration and settlement process of South Asian Refugees 
living in Estonia, to focus on social and cultural aspect in a new society, and to see the impacts of resettlement on refuges. The intention was to generate new ideas of experiences on social and cultural challenges in a new society. To see the experiences of refugee's resettlement, concept of agency and structure has been utilized from a sociological point of view asking the question of how South Asian refugees cope their life in Estonia where the host society's norms and values are different from them. This research tried to find out the answers of these questions on 15 in-depth qualitative interviewswith South Asian refugees living in Estonia.

\section{Theoretical standpoint}

The question of adaptation has produced different sort of theoretical perspectives. For instance Zubrycki, in Richmond(1988) identified six models of migration. Classical approach focused on assimilation and was functionalist in orientation. It contrasted with a Marxian, or conflict model which emphasized class difference between immigrants and indigenous populations. In the early time, the colonial situations produced the elite form of migration; on the other hand in the recent times it has been cross sectional in terms of professional status and diverse in the form of cultural aspect. Recent approaches focused on the phenomenon of stratification and segmentation of labor market (Richmond 1988).

One of the core issues of the refugee movements is the relationship between economic and political determinants of population movement. Theories that we tend to get largely applicable to movements of people from poorer to richer areas, form regions of economic underdevelopment to those experiencing growth. The de jure definition of refugee status used and adopted by various countries in determining eligibility for admission (well founded fear of persecution), it is no longer possible to treat refugee movements as completely independent of the state of the global perspective economy. International relations and ideological considerations are also involved (Weiner 1990). If we look at the large movements of refugees' in current days, they not only include economic but also social and political factors and these cases are interdependent.

Theories of migration have tended to go around structure and agency. Some approach lean towards a more determinist position and plan in regards towards decision and behaviors of individual actors. While many go to the other direction 
and focus on agency of individuals. Some head towards a middle ground recognizing the importance of finding the balance between structure and agency (Bakewell 2010). However, the relationship between structural constraints and individual choice is a central problem in sociological theories. It involves fundamental questions of free will and agency over or against theories which imply behavioral determination by forces over which we have little or no control.

In this study I have explored the theoretical concepts of structure and agency expounded by Anthony Giddens (1984), "it provided the framework for thinking these issues and bringing together Political (Individual, agentic) and sociological (structural, societal)aspect (Nourpannah 2014). Gidden's theory of stracturation proposes an elegant compromise as he argues that structure has a dual nature as both the medium and the outcome of the social practices they recursively organize(Bakewell 2010). It provides the tools to examine the interaction of the individual within the social fabric and 'the theoretical grounding for the "encountering" and "routinization" that form a basis for this fabric" (Nourpannah 2014: 58). To see how the encountering and routinization occurs within the South Asian Refugees in Estonia, interview questions were developed in way to concretize it; how their time being spent? Who do they look around and meet? What are their current practices being refugee when it comes to social and cultural aspect and how they interpret and perceive of received practices assuming that respondents havecommon and uniform social and cultural practices and "indeed for all Muslims" (Moghissi, Rahnema, and Goodman 2009).

\section{Literature Review}

Refugee resettlement is a notion that provides both protection and durable solutions for individuals. Refugees are often considered alongside other migrants when their situations are different (Joly 1996). Many refugees would have preferred to stay in their home country that might even lead to restrict assimilation. Scholarly works that discuss on resettlement uses different terminology that includes: acculturation, biculturalism, multiculturalism, assimilation, integration, settlement etc.

Estonian national integration policy is based on Estonian integration strategy 20082013, which aims to support the feeling of belonging to Estonian Society among residents of Estonia (Saar 2009), it should come through sharing common values 
and command of the state language. Factors that characterize integration can be divided into two parts, structural and subjective factors. Structural factors deals with legal status, labor market etc and subjective factors deal with attitudes, for example sense of homeland, attitude towards cultural diversity, distress about perceived life style of ethnic groups in Estonia (30). Saar(2009) in her study pointed out that over the years in Estonia there has been a relatively stable general positive attitude towards cultural diversity and in this study she shown that most of the Estonians and Non Estonians agree that ethnic groups can have good relations in one country and different languages and cultures enrich society. However, this was a study to show how Estonian and Non Estonian feels on cultural diversity but did not have any particular focus on refugees as Refugees are often considered alongside other migrants when their situations are different (Joly 1996).

Research on immigrants in Estonia mostly focused on Russian speaking first or second generation immigrants putting the emphasize on Educational level of immigrants population, position of native and immigrants population in the labor market, working life of native and immigrant population, ethnic minority and majority unions, political and civic participation of immigrants etc. To examine the relationship between structural, cultural, social and identificational integration dimensions among second generation Russians in Estonia, Nimmerfeldt(2011) and his colleagues identified that in Estonia, relationship between structural and cultural integration is positive and according to this study higher level of social and identificational integration is not related to higher level of structural integration. Second generation Russian retains a strong ethnic identity and socializes primarily with other Russians. Ham and Tammaru(2011) in their research on ethnic minority and majority unions in Estonia came out with a finding that Russian speaking immigrant women are less likely to make a union which according to them is ultimate evidence of the integration of ethnic minorities into the host societies. In a study of political and civic participation of second generation Russian and Estonian Youth, Schulze(2014) pointed out that "Ethnicity remains a significant predictor of political and civic participation. Estonians are more likely to vote in municipal elections and to participate in a voluntary association than Russian."'(19). However, the percentage of individuals with low level of education is lower among immigrants than among native population (Saar 2009). Migration research in Estonian society has been mostly built on Russian speaking immigrant and immigrants on the whole. None of them particularly focused on refugees or immigrants having the ethnic background outside of Europe. 
A study on South Asian Immigrants in Britishsociety, Ghuman (1997) pointed out that majority of young Asian people prefers integration and rejects assimilation, marginalization, and separation strategies. Therefore young South Asians are bilingual and bicultural. They tend to maintain both their own culture and at the same time coped with the host society's norm. They usually identify themselves as 'Indo-English' (69), despite of their preferred integration strategy, 'they continue to suffer racial abuse both in and out of school and have doubt whether they belong English society" (Ghuman 2003, 130).

In a study of preferred life partner and how south Asian immigrants perceived about it, Alexander(2013) in his research shown that when young people start to take an interest in adolescence of opposite sex, Asian parents generally disapprove of dating, particularly when their daughters get involved. "Most of the marriages in Pakistan, Bangladesh are arranged by the family and this custom is still considered by the first generations immigrants in Britain" (Robinson 2005, 187)

Key domains of integration are related to four major themes of achievement and access of employment, health, education and housing. Aspect of integration and resettlement remain divergent from the mainstream literature on 'integration'. Major phenomenon that has been dealt in the scholarly interest is mental health issues when refugees settle into new societies (Nourpannah 2014). They do not provide an in-depth argument of how cultural aspect could shock from the stressful and precarious resettlement procedures as refugees resettled from different countries to Estonia and could be associated with mental issues.

In the process of resettlement, migrants face different culture, ways of living, and in cases prejudice, previous research has shown that "homesickness and fear of persecution may continue long after migration." (Nann 1982). In a study of Bosnian Muslims families, Witmer and Culver(2001) critically reviewed the existing literature of refugee's mental health and brought out the argument that available research mostly focused on post traumatic stress disorder and very few studies addressed adaptation and resiliency.

In a study of Afghan refugees and their adaptation in Canada, Stack and Iwasaki (2009) pointed out that Afgan refugee are marginalized minority who face substantial stress in the process of adaptation. Nourpanah (2014) However in her study of the experiences of Afghan refugees who have settled in Canada pointed out that Afghan refugees build upon the structures available to them and practice 
both culture. The underlying motive of how to practice both culture while developing a sense of belonging in Estonia, will be discussed in the research findings.

\section{Methodology}

15 open ended interviews were conducted withPakistani, Bangladeshiand Afghan Refugee Muslim families who have settled in Estonia over the past eight years. Interviews were conducted from February 2015 to May 2015. All interviews took place in a family setting and answering the question collectively. Prior appointments were taken and interviews took place in the interviewees place. 13 Interviews were taken in Hindi and Urdu, the languages commonly spoken and understood all over South Asia and were transcribed in English. 2 interviews were conducted in Bangla which is my native language. For the quotation, anonymity and confidentiality has been ensured throughout the study.

Qualitative method has been deployed for this study as it is suited to document refugee's experiences and to provide a space to document the voices of refugees. "Qualitative method could reveal that immigrants have distinctive histories and that they are economically, socially and politically differentiated" (Barber 2003).

Refugees are difficult to access and quite often they are call 'invisible actors' (Bond and Voutira 2007). A country like Estonia, immigrants who are from South Asia can be identified as it has very small number of immigrants from outside Europe but at the same time it is really difficult to access as authors pointed out that "perhaps they are visible and can be identified but largely inaccessible for researchers for different reasons" (283). Refugees live in Estonia are free from Institutional control and are provided support person to get settled in Estonia for the first two years of their permission as a refugee status. Once I gained access to participants through asupport person, I continue establishing rapport with the participants that proved worthy. This study was not done to research a community, it was rather a study of a set of familymembers from South Asian background refugees, and therefore I didn't have to rely on any point of entry or particularly any "snow ball sampling method to reach out a community" (DeWalt and Dewalt 2011). 


\section{Preserving the culture}

As soon as I got into the homes of my participants I was struck by the fact that how culturally specific furnishing and decorations were: pictures of kaba sarif, a holly place for Muslims; handmade sofa covers; pictures of famous place sahid minar, a monumentin Bangladesh to remember the great heroes who died in the language movement; beautiful mosque's photos were hanging on the wall. Of the female participants Farjana, Rokeya, Khatun and Bushra were fully covered and were completely in veil with different kind of embroidery on top of their Burkha, A tent like garment worn by women that covers complete body. Laila, Abida and Raka were dressed with Shalwar Kameez which is a traditional dress originated in South Asian and worn by women and this dress is generally viewed as different styles and doesn't cover whole body. Abida also hadOrna which is a small piece of garment that used to be worn to cover the middle part of the body so that female sexual organ is not exposed, which Abida explains- "I am wearing a three piece,Shalwar, Kameez and Orna. If I just only were two pieces of Shalwar and Kameez, itdoesn't look good and it exposes the body". Kulsum, Mithila and Rahima were dressed in very much casual western outfit with a simple t-shirt and jeans pant with no veils. From these small number of women respondents, what is evident is that the striking differences of their clothing, which is an ongoing issue considering the fact that how politicized on the women's clothing in religious and non religious term. Despite the fact of own preferences and own beliefs in a new society, their identity remained quite firm as 'South Asian' not only offclothing but also visual effects.

\section{Socio-cultural domains: Marriage, Friends and Family}

"Honor killing" has been a catchy word by the media, especially societies where the number of immigrants are high, a word that describes how daughters of immigrants with Muslim background coming from South Asia or Middle East being abused and at times killed by the family members for having boyfriends or not being obedient of arranged marriage. Cohen wrote on Vancouver Sun that "honor killings have been on the rise in Canada". It was off interest to see how South Asian parents have been dealing their children in Estonian culture. 
Respondents in this study were very much concerned about their religious identity. All families of this study seemed to have receptive mood of their children choices and they are very much concern about the fact that they cannot just force their children in this society and at the same time their wish is to teach children the way they want them to practice their religious and cultural values and to keep that uphold. Hasan, a male respondent of this study, who is 45 year father of two daughters, pointed out that- "When I die, I will have to answer Allah, what did I do for my children. So my duty as a father is to educate them and to teach religious culture. I am doing my job. If they don't want to continue, when they are grown up; it's their choice, I will never force them." His daughter goes to swimming lesson at a local swimming pool, which could be barely seen in their home country. "Her all friends go this swimming lesson, I cannot just suppress her", says Hasan. It is an instance of integration, as it refers when there is an interest in both maintaining one's heritage culture in daily interactions and with other groups. (Berry 1997). An indication of adaptation of individual motive on received culture.

Taswar, who is a 35 year father, a devout Muslim, practices Islamic rituals very consciously so that his children learn it from him. "I and my wife always pray at home, my wife does Hijab, covering whole body". He hopes that his son and daughter would follow them, they are now under 5 year of age and he believes this is the time when children start learning from their parents. "I never forced my wife to wear veil and I would never force my daughter"; Taswar looks at his wife Khatun, who smiles proudly and added "it's not that all women in South Asia wear a veil, it's an individual choice".

According to Mithila, who is a house wife and looking for a job, "In south Asia a lot of girls and boys are now getting married on their own choice". She explains it as "love marriage"- A kind of marriage when husband and wife know each other before marriage but doesn't have any physical relation or living together, what she explains as "I have a love marriage", but getting marriage beyond parents consent remains strict for Mithila as she explains "I had to convince my parents, and expect my children to do that as well". Children to go free and hang out with friends over night remains strict for Mithila, 'I don't like my children to go too free'.

This generational issue doesn't seem only religious but tradition of family interest to keep it extended. "In our tradition parents live with their children, especially with son, even after when son gets married. I want to stay with my child when I get older and I hope they will look after me." Says Mithila; but at the same time she 
accepts the fact that it might not be the case when children grow up as she believes in Estonia everybody gets split up after reaching 18, "if my children get married without consulting me, I can't do anything" she also adds, "it could happen to any family".

Young adult respondents seemed quite obedient of their parent's expectation, "I have Estonian friends and I enjoy with them at school" says Rokeya who is a 14 year girl. Regarding question of how she socializes with the Estonian friends in the context of bringing them at home, "I don't invite my friends to come home. If someone wants to visit, I ask my parents first" says Rokeya with a short smile while looking at her parents. She seemed quite skilled at defusing tentative family matter.

Mahmud a nine year boy who goes for Basketball learning and has got quite a few Estonian friends expressed his opinion upon being asked how he perceives about his friendship with others, "I used to visit my friends home often and their parents are really nice at me". He continues expressing his view looking at his father "I hope I would be able to invite my friends regardless their gender". The observation is as such that a boy could have a friend with a same gender but having a friend of opposite gender and bringing them at home remains strict for them. Negotiation plays a significant part in the family life as Povey(2007) in her study on Afghan refugees mentioned that "in the western countries children and parents make negotiations and concessions", therefore it doesn't remain one sided.

Maruf a 42 year respondent who is a sociology graduate proudly mentioned that "I teach both my daughter and son Qran, and they both already pray five times a day." His five year son and seven year daughter both goes to Estonian school but he did not mention it in the first place while asked about his children. Religion plays a big part of Maruf's life as he mentioned "religion is everything for me."Maintaining host societies values and at the same time keeping own religious belief and going with traditional rituals seemed acceptable for Maruf. "My wife is looking for a job here and I don't think it's bad for women to go out." For Maruf, the significant part of his social and family life is how he interprets religion and it has to be dealt in a new society. The term of sex and marriage is very much in this society what in his concept "western values" but "one has to cope with it and will have to practice own values accordingly" says Maruf. In some circumstances dual life in a context to live within a family and of social life remains significant for refugees, as 
Povey(2007) identified that sometimes concession and negotiations within a refugee family life could lead double lives.

Asad, a recently married man informed during a discussion period that the notion of family honor among the south Asians in Estonia is relatively fewer, he thinks it is because "the number of South Asian immigrants are few" something what he thinks that "if the community is big, notion of family honor and prestige becomes bigger." Boys don't seem as much affected as the girls are in terms of religious and traditional notions, as Asad says "religious affinities and traditional aspects have positive correlation with the girls in the community."

The willingness of female education and the issue of sending them school and working outside the family is a significant indicator of the cultural adaptation of South Asian families in Estonia. Female education has been highly politicized in south Asia, while women's right remains in controversy and women's role in the kitchen and household being emphasized for the "physical and social well being of household members" ( Hole 2005: 146). Rahima a 19 year girl sitting beside her parents, without any hesitation says "My plan is to finish my education first; I want to be an architect. I don't have any plans to get married now". This is not just an indicator of the second generation's willingness of education but also stepping away from the cultural boundaries being refugees and pushing them into an open window. They no longer belong to a society where only the male counterpart would make the ultimate decision on women. Even though parents do have their preferences as per their children's choices as it could be evident in any societies but this doesn't prevent them to think and to do what they want. 'I know what my parents want, but at the end of the day it's my life' says Rahima.

Between generations in this study, parents and their children and their understanding in regards to religious norms and cultural traditions seemed a reciprocal understanding and it can be brought up as mutual understanding and can be argued as tolerant accommodation within the family. Parents and children's have respect for each other as parents have their own preferences but they do believe that at certain point it's the children's own decision and on the other hand children's tend to understand the overall appeal and very much sensible of their values. As they adapt with the fact of friends not being allowed at home, makingthe statement by parents that they are not being forced rather of a mutual understanding and at the same time they admit that they are free to chose their academic studies and when they grow up they would decide what they want to do 
in their career. Overall, these both ways interaction had a form of unique South Asian feelings and at the same time Estonian essence is present in thinking process.

\section{Islam as mere religion and religion as custom}

Immigrants from different background might have different opinions and attitudes of relating to Islam as cultural, social, political and religious system (Sharmin 2008) and this is evident from this research participants. Out of fifteen families, ten were verbally and visibly religious than others and it was evident from discussion sessions. "For me religion is everything. Whatever I eat, whatever I do; I try to do it in terms of religion" says Asad while looking at his wife who is completely covered by veil. Social aspect has been emphasized by Tastsoglou(2006) mentioning "religion could ease social integration of migrants" (220). Even though, going to the Friday prayer is not necessary but it is significant in social and political values and gives them social integration. "I always send my five year son to the Friday prayer with his father so that he could get to know others" says Asad's wife. It seemed, has spiritual aspect in it and at the same time cultural and the political aspect, "if I don't take my son with me to the Friday prayers, other community members might think that I don't want to raise my son with proper religious and cultural education" says Asad.

Islam(2008) Emphasized on how individual interpretation is significant in terms of religious practice. Dossa(2008) pointed out how religion could help individuals to organize their time and space. It was evident in this study aspracticing Islam helps them to adapt the uncertainties in new societies and face the challenges. Quite often they are worried about the next generation, whether they would keep up their culture which they believe based on religion, "I wear Burkhaand I pray five times in a day, it gives me pleasure and I hope my children would learn it from me" says Laila. For her whateverhappens, happens for the best, "I am satisfied with whatever Allah has provided me in my life" as Marf uses the word "Alhamdulillah" which is an Arabic word used to express thankful to god.

Religious identity does not appear core point for other families. Conviction on religion seemed quit reluctant, Friday prayers doesn't seem too important for them. "I go to eid(religious festival) prayers twice in a year but that's all" says Hamid, a young newly married man. For him, this is the way he was brought up and religion 
doesn't play a part in his social and cultural life. "I got information from a web site that Estonia is number one, in terms of not having religious influence on social, political life, I am a part of this society now and I would love to follow it" says Hamid.

Dressed up with full hijab, fully covered dress appeared just a matter of "used to" for Sahana 35 year old woman. "I feel comfortable with hijab this is the way I am used to", religion is not so important, she advanced pointing out that "I have to learn Estonian language, will have to get some training from this society to get a good job rather than focusing on religion." These families food habits seemed south Asian flavors which they incorporated with more of a custom which is an integral part of their life than religion.

One family appeared non-religious. The female appeared in western outfit and there was no religious symbol in the house or any ornaments worn by anybody. It has be to be mentioned that for a family coming from that part of the world where religion plays significant role in public and private sphere, stepping forward and stating as non religious family has a social significance. A woman appearing with western outfit and making points of what she likes or dislikes is quite a statement as (Nourpannah 2014) stated that "assuming a non-religious identity for people from countries where religion plays a part into their constitution can be seen as agentic."(64). for this family, not all people in South Asia are religious. It's just the political parties who are making the profit in it. "As most people in South Asia are uneducated and poor, political parties are making full advantage using religion into politics" says Anufa. When the question was directed on adaptation and culture, Anufa's husband says "I am willing to accept anything that comes across and I feel will be good for me and my family".

Thus, Individuals affiliations on religion in this study have been in different degrees and it's a construction for individuals, which seemed agentic by which they at times show their identity, willingness and compassionateness. On the other hand individuals focused on their individuality by contrasting to other stating what they think of religion and how insignificant it is for them.

\section{Conclusion}

Gidden's term appeared strong in impression through the participants of this study. They are selective of what they adapt in their cultural and social life and regarded 
as highly "south Asian" and extend their desire to adapt Estonian culture to a certain extent what they believe will be significant for them. They admit what they have gone through being refugee and for existence they need to cope with different anticipation in a new society.

Refugee families and reconstruction of their lives of individual preferences and differences of thinking level have been evident through this study that emphasizes heterogeneity of relatively homogenous participants which is meaningful through their daily life and practices. Whatever structures they carried in the form of religion and available to them in the form or education and decision making in a new society; they build it up and practice their agency through that to make their structure.

\section{References and notes:}

Alexander, C. 2013. "Marriage, Migration, multiculturalism: Gendering 'The Bengal Diaspora."Journal ofEthnic and Migration Studies 39(3): 333-351.

Bakewell, O. (2010) "Some Reflection on Structure and Agency in Migration Theory" Ethnicand Migration Studies. 36(10): 1689-1708.

Barber, G.P. (2003) "Citizenship and Attachment across Borders? A Transnational andAnthropological Research Agenda." Canadian Diversity. 2(1): 46.

Berry, J.W. (1997) "Immigration, Acculturation, and Adaptation: Applied Psychology". AnInternational Review, 46, 5-34.

Bond, H.B.; and Voutira, E. (2007) "In Research of Invisible Actors: Barriers to Access in Refugee Research.” Journal of Refugee Studies. 20(2):283.

Chimni, B.S.(2000) "Globalization, Humanitarism and the Erosion of Refugee Protection” Journal of Refugee Studies 13( 3):243-263. doi: 10.1093/jrs/13.3.243.

Dandy. J.(2009) "Refugee and Migrant Integration: Examining the Discourse of the Dominant" Tamara Journal for Critical Organization Inquiry Vol 8 Issue 8.2: 225233.

DeWalt, M.K.; and SDeWalt, R.B. (2011) Participant Observation: A guideline of Fieldworkers. Rowman \& Littlefield.

Dossa, P(2008) “Creating Politicized Spaces. Afghan Immigrant Women's Stories of Migration and Displacement." Affilia 23(1) 10-21. Doi-

10.1177/0886109907310462.

Estonian Human Rights Center (2015) Refugees, available (http://humanrights.ee/en/refugees/ ). Accessed on $19^{\text {th }}$ May, 2015.

Eurostat Newsrelease (2015) Asylum In the EU, Available http://ec.europa.eu/eurostat/documents/2995521/6751779/3-20032015-BPEN.pdf/35e04263-2db5-4e75-b3d3-6b086b23ef2b accessed on $19^{\text {th }}$ May 2015. Ghuman,P.A.S. 1997. "A Study of Identities of Asian Origin Primary School Children." Early Child Development and Care 132: 65-75. 
Ghuman,P.A.S. 2003Double Loyalties South Asian Adolescents in the West. Cardiff: University of Wels Press.

Ham, M.; and Tammaru, T. (2011) "Ethnic Minority-Majority Unions in Estonia." Eur J Population 27: 313-335. doi-10.1007/s10680-011-9236-z.

Hole, E.A. (2005) Neither Here-Nor There: An Anthropological Study of Gujrati Hindu Women in Diaspora. Sweden: DICA.

Islam, A. (2008) Acculturation Preferences among Bangladeshi Immigrants living in Malmo and London. Lund University, Sweden.

Joly, D. (1996) Haven or Hell? Asylum Policies and Refugees in Europe.

Basingstoke:Macmillan.

Marian,M. (2015) "Estonia Not on the Refugee Way" Inter Press Service News Agency. Available (http://www.ipsnews.net/2013/06/estonia-not-on-the-refugee-way/) accessed on $19^{\text {th }}$ May 2015.

Moghissi, H.; Rahnema, S.; and Goodman, M.J. (2009) Diaspora By Design: Muslims in Canada and Beyond. Toronto University Press, Canada.

Nann, C.R. (1982) Uprooting and Surviving: Adaptation and Resettlement of Migrant Families and Children. Dordrecht, Holland: Reidel.

Nimmerfeldt, G.; Schulze, j.; and Taru, M. (2011) “The Relationship Between Integration Dimentions among Second Generation Russians in Estonia." Studies of Transition States and Societies. 3(1): 76-91.

Nourpanah, S. (2014) “A study Of The Experiences Of Integration And Settlement Of Afgan Government-Assisted Refugees in Halifax, Canada" Refuge 30(1): 57-66.

Nyers, P. (2006) Rethinking Refugees: Beyond States of Emergency. New York: Routledge. Povey, R. E(2007) Afghan Women: Identity and Invasion. ZedBooksLtd. London. UK.

Richmond, A. (1988) "Sociological Theories of International Migration: The Case of Refugees" Current Sociology 36(2): 7-25. doi:10.1177/001139288036002004

Robinson, L. 2005"South Asian in Britain: Acculturation, Identity, and Perceived Discrimination.” Psychology and Developing Societies 17:181.

Saar, E, ed. (2009) Immigrant Population in Estonia. Statistics Estonia, Tallinn.

Schulze, L. J. (2014) “The Ethnic Participation Gap: Comparing Second Generation Russian Youth and Estonian Youth.” Journal of Ethno politics and Minority Issues in Europe.113(1) : 19-56.

Sharmin, Z. (2008) Beyond the Root: An Endless Journey. Lund University, Sweden. Tastsoglou(2006) Gender, Migration and Citizenship. Saint Mary's University, Canada. UNHCR Regional office, (2015) UNHCR, The UN Refugee Agency. Availablehttp://unhcr.org.au/unhcr/index.php?option=com content \&view=article \&id=179\&It emid=54 accessed on $18^{\text {th }}$ May, 2015.

UNHCR Northern Europe, (2001-2015) UNHCR, The UN Refugee Agency. Available (http://www.unhcr-northerneurope.org/where-we-work/estonia/) accessed on $18^{\text {th }}$ May, 2015.

Weiner, M. (1990) Security, Stability and International Migration. Center for International Studies, MIT. Available http://web.mit.edu/ssp/publications/working_papers/WP90-2.pdf 
Witmer, T.AP. and Culver, S.M (2001) "Trauma and Resilience among Bosnian Refugee Famillies:A critical Review of The Literature.” Journal of Social Work Research and Evaluation 2: 183-188.

\title{
Summary
}

\section{A study of South Asian Refugee's Settlement Experiences in Estonia}

\author{
Aminul Islam \\ Tallinn University, Estonia
}

This paper presents the experiences of South Asian refugees in Estonia and their subsequent settlement procedure by using Anthony Giddens's concept of Structure and Agency. Investigation was carried out by a qualitative approach with a sample of South Asian refugees who have settled in Estonia. Focus was to address how respondents express their agency within a given structure of a new society. In light of the outcomes, individual preferences and differences of thinking level was evident and it is argued that they form heterogeneous presence in contrast to what they are being portrayed of mere victims or sufferers by general understanding.

Keywords: Refugee, structure, agency, South Asia, Islam, settlement, Estonia 